\title{
The case of cholera preparedness, response and prevention in the SADC region: A need for proactive and multi-level communication and co-ordination
}

\author{
MD Said ${ }^{1}$, N Funke ${ }^{2 *}$, I Jacobs ${ }^{2}$, M Steyn $^{2}$ and S Nienaber ${ }^{2}$ \\ ${ }^{1}$ Euroconsult Mott MacDonald -Technical Assistance Support Team (TAST), Ministry of Water Resources \& Irrigation, \\ PO Box 476, Juba, South Sudan \\ ${ }^{2}$ Council for Scientific and Industrial Research, Natural Resources and the Environment Unit, PO Box 395, Pretoria 0002, \\ South Africa
}

\begin{abstract}
In this paper the authors seek to identify the most appropriate model for a regional co-ordination mechanism for cholera preparedness, response and prevention. The qualitative mixed-method data collection approach that was followed revealed the need for alternative solutions, including a socio-political understanding of cholera responses at different levels of scale and at different stages of an outbreak. Important areas that need to be understood include the multiplicity of actors and the complexity of their interaction, the importance of building local capacity, the need for varying responses at different levels of scale, the need for improved inter- and intra-country co-ordination and information exchange, the importance of cultural belief systems and the impact of the media on the response to cholera outbreaks. Ultimately, despite the proposed co-ordinating role that the Southern African Development Community (SADC) can play in a regional cholera response effort, the onus remains on states to build capacity at the local level and to capacitate local communities to drive response efforts semi-autonomously.
\end{abstract}

Keywords: Cholera prevention, preparedness and response, socio-political understanding of cholera, socio-cultural understanding of cholera, transboundary disease, Southern African Development Community (SADC), cholera

\section{Introduction}

Africa accounts for over $90 \%$ of all cholera cases reported to the World Health Organisation (WHO, 2007). Gaffga et al. (2007) refer to Africa as the new homeland for cholera, as cholera outbreaks have been reported on an annual basis since 1990. The SADC region is therefore a prime case study area for observing regional responses to cholera, particularly due to the transboundary nature of the disease, which poses a health security risk to almost all of the SADC member states. Cholera epidemics are cyclical, seasonal, and have been reported annually in several Southern African states since 2000 (WHO, 2006). The recent outbreak that originated in Zimbabwe in August 2008 resulted in 98424 suspected cases and 4276 deaths in the country, as reported on 30 May 2009 by the Ministry of Health and Child Welfare in Zimbabwe (WHO, 2009). Nine other countries in Southern Africa were also affected by cholera, either as a result of the Zimbabwean outbreak or independently of it. These countries were Angola, Botswana, Malawi, Namibia, South Africa, Swaziland, Zambia, Zimbabwe and the Democratic Republic of the Congo (DRC) (Kiem, 2009).

The fragile socio-political and environmental situation of many Southern African states makes the region particularly susceptible to cholera outbreaks. In addition to weather patterns conducive to the outbreak of cholera, a history of labour migration, lack of adequate sanitation in informal settlements and rural areas, failed or failing health care systems, inadequate community involvement, poor domestic and personal hygiene, lack of capacity at the local government level, lack of logistical

\footnotetext{
* To whom all correspondence should be addressed.

푤 +27 12 841-2024; fax: +27 12 841-3954; e-mail: nfunke@csir.co.za

Received 27 September 2010; accepted in revised form 7 October 2011.
}

co-ordination of relief aid, cultural stigmas regarding treatment of cholera and political instability in several states are all factors that have contributed to the increase in outbreaks (United Nations Office for the Co-ordination of Humanitarian Affairs, 2008; Mintz and Guerrant, 2009). This has raised concerns about regional security as well as the role and preparedness of the SADC states in addressing health emergencies of a transboundary nature.

This paper reviews the presence of epidemic cholera in the SADC region and is based on research conducted to identify the most appropriate model for a regional co-ordination mechanism for cholera preparedness, response and prevention. At the outset, the research team hypothesised (based on a preliminary literature review) that the responsibility for establishing and running such a mechanism would likely be situated at the regional (i.e. SADC) level.

This hypothesis was, however, challenged by the qualitative mixed-method data collection approach that was adopted during the project. The research results revealed the need for alternative solutions that include a socio-political understanding of cholera response at different levels of scale and at different stages of an outbreak. Priority areas include: understanding the multiplicity of actors and the complexity of their interaction, the importance of building local capacity, the need for varying responses at different levels of scale, the need for improved inter- and intracountry co-ordination and information exchange, the importance of cultural belief systems, and the impact of the media on the response to cholera outbreaks.

The authors summarise these findings and further argue that, despite the proposed co-ordinating role that SADC can play in a regional cholera response, the onus is still on states to build capacity at the local level, develop appropriate preparedness plans, review them periodically, and share this information with other states in the region. Here it is important to recognise that while state action is required to provide systems for 
inter-state co-ordination, local communities need to be capacitated to drive response efforts semi-autonomously.

\section{Methodological framework}

The authors adopted a qualitative, descriptive analysis of regional responses to cholera. This approach was adopted for several reasons. Firstly, the body of literature on cholera in SADC is voluminous; however, it has been conducted from a largely scientific point of view. More specifically, cholera outbreak response research has focused on medical aspects that are important for decreasing mortality (WHO, 2004a). Due to the fact that outbreak response is often led by medical professionals, other aspects, such as environmental and communication issues, have often been neglected (WHO, 2004a). This has largely resulted in the omission of socio-political and socio-cultural perspectives. The lack of publicly-documented and accessible research on multi-actor response and multi-level co-ordination strategies provides critically important gaps in scientific research and policy, and subsequently the need for more integrated analyses. A more comprehensive response is needed to limit the spread of the disease, and a trans-disciplinary descriptive analysis of the nature of the problem is therefore essential to highlight the linkages between scientific, socio-political and socio-cultural dynamics and policy.

Secondly, it is apparent that a vast treasury of experiential knowledge exists in the minds of key individuals working in the field of cholera response strategies in the region. However, this knowledge is seldom captured. Participatory engagement was therefore identified as an appropriate research method to retain the experiential knowledge of these individuals.

The method employed was divided into 2 phases: a literature review and qualitative participatory engagement. The literature review included an analysis of primary and secondary sources including policy documents, popular articles and academic articles. Qualitative participatory engagement comprised of a multi-stakeholder workshop, observation of governmental committee meetings in South Africa, qualitative interviews and several other consultative processes.

The chosen methodological framework brings to the fore the socio-political and socio-cultural issues that are often forgotten, ignored or undermined, but that play a critically important role in determining the success or failure of technical and sciencebased interventions.

\section{The context in which cholera occurs}

\section{Cholera the disease}

Cholera is an acute dehydrating diarrhoeal disease caused by ingestion and colonisation of the pathogenic strains of the gram-negative bacterium, Vibrio cholerae. Although more than 180 serogroups of $V$. cholerae exist, only 2 serovars - O1, and less commonly O139 - have been linked with epidemic disease (Wachsmuth et al., 1994; Lin et al., 1999; Du Preez et al., 2010). A serovar refers to distinct variations within a subspecies of bacteria or viruses. A group of serovars with common antigens is called a serogroup (The American Heritage Medical Dictionary, 2007).

Vibrio cholerae non-O1 serogroups were until fairly recently only associated with sporadic diarrhoea cases and not known to cause diarrhoea epidemics. In 1992, however, toxigenic strains of the O139 serovar appeared in India and Bangladesh as the first non-O1 serovar to cause epidemic cholera (Albert et al., 1993; Ramamurthy et al., 1993; Lin et al., 1999). While the possibility of a Cholera O139 outbreak has not been associated with Africa, the recently-published Du Preez et al. (2010) study found both strains in estuarine waters and sediments of Mozambique, now also linking the O139 strain to African waters and indicating a possible human health risk.

While $V$. cholerae is a natural inhabitant of estuarine environments (Colwell and Huq, 1994), humans are the only known natural host for $V$. cholerae, and the disease is spread mainly by faecal contamination of water and food. Direct person-to-person spread of the disease is uncommon (Hensyl, 2000). The incubation period varies between 6 hours and 5 days. Oral rehydration therapy (ORT) is the treatment of choice as it is effective, economical, easy to administer and capable of reducing the case fatality rate (CFR) to less than $1 \%$ (WHO, 1993). However, despite the existence of basic treatment solutions, cholera is still not being prevented or controlled, especially in developing countries.

\section{Cholera and water quality}

Cholera is associated with several socio-economic factors, such as population density and poverty, and is closely linked to poor sanitation and hygiene, and a lack of a safe, clean water supply (WHO, 2010). In addition, basic measures to improve water quality such as boiling, chlorination, and filtration are not economically feasible for many rural or peri-urban communities, and sanitation targets are still lagging behind in sub-Saharan Africa countries (United Nations, 2009). Waterborne transmission has been quoted as being the most important route of transmission in Africa, with several researchers linking cholera to untreated drinking water from contaminated water sources such as lakes, rivers, springs and shallow wells (Bradley et al., 1996; Shapiro et al., 1999). In rural environments, contaminated water sources transmit the disease to the communities through which they flow, while in urban and peri-urban communities, cholera outbreaks are usually caused by breakdowns in water treatment systems and/or contaminated public water supplies.

In addition, the relationship between cholera and poverty is well documented and remains a global threat, especially in the developing world (Borroto and Martines-Piedra, 2000; Soussan, 2003). The most susceptible individuals tend to be those living in poor communities characterised by economic and social hardships. Roughly $70 \%$ of people in the SADC region, and $60 \%$ of people residing in poor rural communities, are dependent on groundwater for domestic water supply (Banda, 2009). However, only a few SADC countries actively monitor groundwater use effectively and manage it sustainably. In the absence of effective monitoring and surveillance systems and streamlined reporting procedures, little can be done to curb the contamination of groundwater that exposes millions of people living in rural areas to waterborne diseases (Zuckerman et al., 2007; United Nations Office for the Co-ordination of Humanitarian Affairs, 2008; Banda, 2009; Mintz and Guerrant, 2009).

Access to clean water is not only a rural problem, however, and also affects many urban populations across the SADC region as governments fail to replace poor infrastructure (Banda, 2009). On average, the provision of rural water supply has improved considerably in the last decade, with access to improved water sources having increased from $56 \%$ in 1990 to $64 \%$ in 2006 in Africa (WHO, 2008). However, in some countries, such as Zimbabwe and Zambia, urban water services coverage has in fact decreased (Fig. 1). This is presumably due to urban migration and rapidly increasing urban populations, 


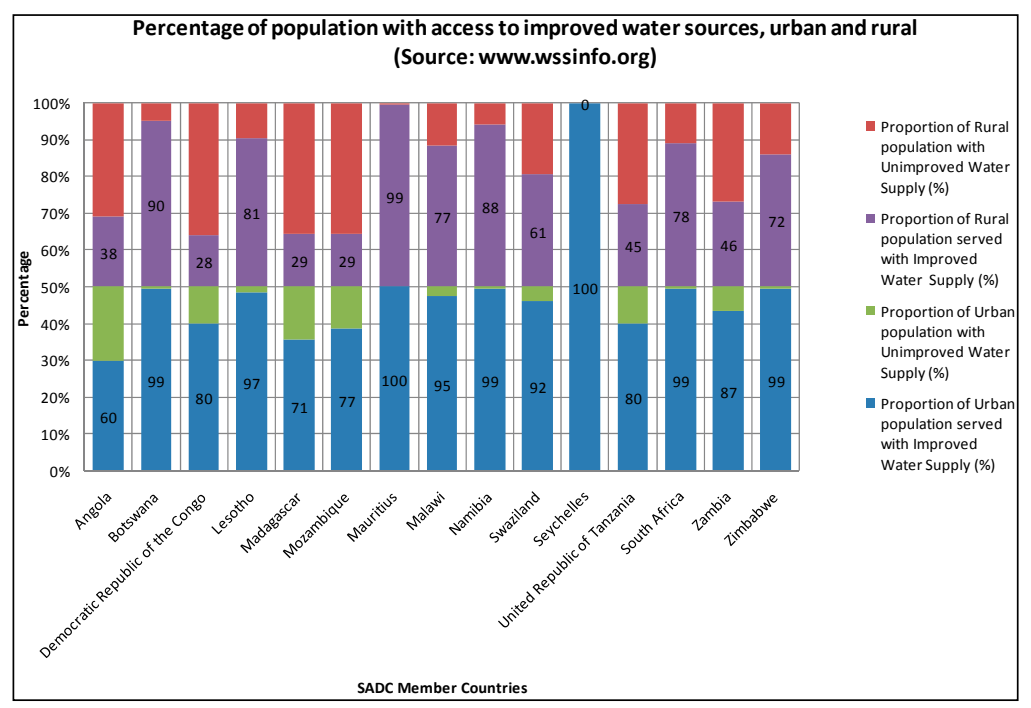

Figure 1

Reported percentages of populations in SADC countries with access to improved water sources, urban and rural (Source: WHO, 2008)

as well as the failure to meet the increasing demand for water supply. The deterioration of existing water services due to poor maintenance may also contribute to the problem.

Reported statistics such as those represented in Graph 1 must be examined with a degree of caution in that they prioritise water access above water quality. For example, the graph indicates that a percentage of a population has received access to improved water sources in urban and rural areas. However, this information does not clarify whether the service is still functioning and when last it was monitored, whether the water supplied is of an appropriate quality, and how often quality standards are not met, as well as for how many hours a day the service is rendered. In Zambia, for example, urban water supply ranges between 5 and 20 hours a day in many towns. Bartram and Cairncross (2010) argue that health benefits are closely linked to the level and quality of service and that the Millennium Development Goal (MDG) for water is inadequate as it assumes water quality to be safe when supplied from an improved source. Thus, the figures provided must be read carefully to understand the limitations on the information that they provide, and the possible areas of poor water quality hidden within these figures.

In summary, the link between water quality and prevention of waterborne diseases is well documented, although the priority for many governments in developing countries to achieve broad-based water access has often masked the challenge of providing water of a suitable quality, and of regularly monitoring that quality. Much of the SADC region still struggles to strike a balance between water quantity and quality with the primary focus still being on access to water rather than its quality.

\section{Challenges in the SADC member states}

Despite the fact that cholera is a preventable and treatable illness, the SADC region continues to be plagued with annual outbreaks (United Nations Office for the Co-ordination of Humanitarian Affairs, 2009; Funke et al., 2010). Why does this problem continue to exist?

Firstly, cholera has become an inherent part of the biophysical environment (Funke et al., 2010). This means that the bacterium reoccurs on a regular basis, often appearing to be triggered by fluctuating weather patterns involving heavy rain or dry seasons (United Nations Office for the Co-ordination of Humanitarian Affairs, 2008; Mintz and Guerrant, 2009). Secondly, cholera thrives in an environment where there is poor infrastructural development, particularly in terms of running water, sanitation and health services (Funke et al., 2010). This makes SADC particularly vulnerable to cholera. Thirdly, notwithstanding cholera cases in Africa being a manifestation of poor infrastructure, the CFR is also a reflection of the inadequacy and inaccessibility of basic health care (Mintz and Guerrant, 2009). A case in point is Zimbabwe, where the CFR for cholera was reported at 5.4\% from 15 August to 18 December 2008. This situation was provoked and accentuated by a lack of safe drinking water and sanitation, as well as inadequate health services (United Nations Office for the Co-ordination of Humanitarian Affairs, 2008; Mintz and Guerrant, 2009). In terms of health care, capacity also varies to a large degree. Lack of resources, internal conflict and limitations of technical expertise are some of the challenges that affect the functioning of medical services.

Also, as a preventative measure, there has historically not been much support for mass vaccination and chemoprophylaxis, as these have been observed to be ineffective in preventing and controlling cholera in populations with endemic disease. However, more recent findings have revealed a proven efficacy and tolerability in mass vaccination and, indeed, a resurgence of this method's popularity in curbing cholera spread as a result of improved and modified vaccines (Sack et al., 2004; Longini et al., 2007; Sur et al., 2009; Zuckerman et al. 2007). The WHO currently recommends pre-emptive use of cholera vaccination in certain endemic and epidemic situations, although clear guidelines have yet to be developed (WHO, 2004b; Zuckerman et al., 2007).

The logistics of rolling out such campaigns are also challenging, especially in rural areas (WHO, 1993; WHO, 2000). Challenges include the need to: recognise the outbreak; rapidly mobilise resources to the affected area; dispense antibiotics or vaccines to the affected population; and followup with patients to confirm that the intervention has been appropriate and effective. Administering mass vaccinations alone, however, will not prevent and control the spread of cholera. Policy-makers also need to be mindful of how poor infrastructure and health services may impede the efficacy of these vaccinations.

Fourthly, cholera affects the entire SADC region because it has profoundly transboundary dimensions (Funke et al., 2010). Its movement across borders in the region occurs for 2 main reasons. In the first case, the Southern African region has experienced a culture of legal, illegal and refugee migrations for more than 150 years, a pattern which continues to grow despite official attempts to regulate it (Gorbachev, 2002; Crush and Frayne, 2007; Swatuk, 2009). Migrant populations such as farm workers have been among those listed to be at high risk of contracting cholera, especially during harvest periods, as working and living conditions are poor and their only sources of drinking water are contaminated rivers and canals (United Nations Office for the Co-ordination of Humanitarian Affairs, 2009). These workers have also contributed to the spread of the disease to rural villages when they return home on periodic visits to family. 


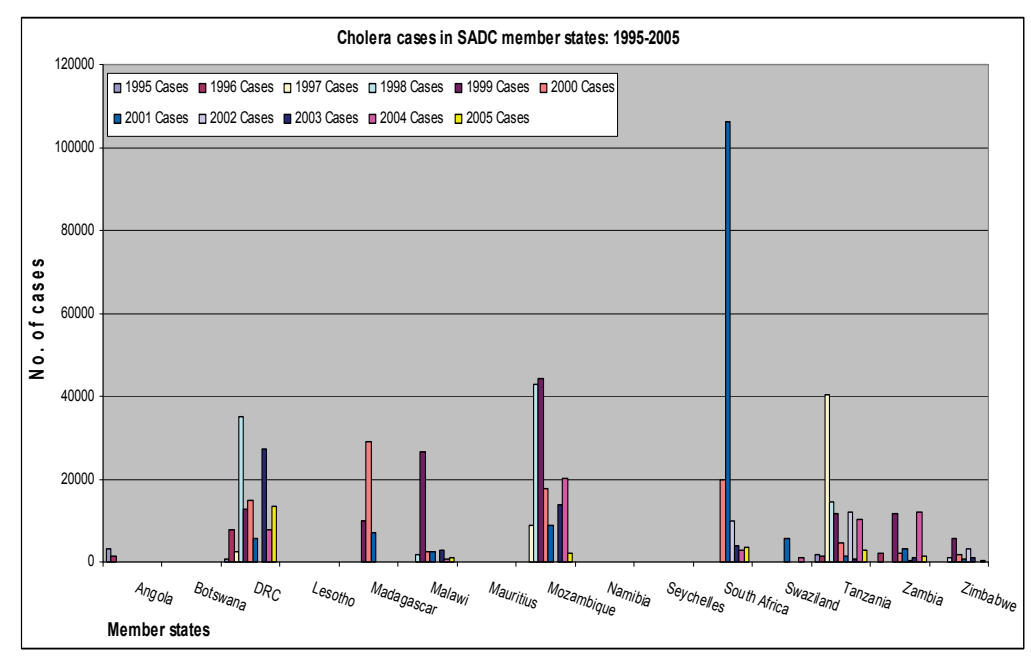

Figure 2

Reported annual cases of cholera in SADC member states between 1995 and 2005 (Source: WHO, 2006)

\section{Cholera epidemics in SADC member states}

Since 1970, when the first cholera outbreak of the seventh global pandemic was documented on the African continent, a number of SADC member countries have been affected (Goodgame and Greenough, 1975; WHO, 2001).

In 2000, 27 African countries notified the World Health Organisation (WHO) of cholera outbreaks. According to the WHO Weekly Epidemiological Records' annual cholera case summaries of 1995-2005, all SADC countries, with the exception of Botswana, Lesotho, Mauritius, Namibia and Seychelles, reported cholera (WHO, 2006). Figure 2 shows the magnitude of the cholera epidemics within this period.

The August 2008 outbreak of cholera in Zimbabwe rapidly spread to the neighbouring countries of Mozambique, South Africa and Botswana and later also affected Angola, Malawi, Namibia, Swaziland, Zambia and the DRC. The situation was aggravated by the influx of illegal immigrants into South Africa, coupled with inadequate water and sanitation facilities and poor hygiene at temporary processing centres for asylum seekers (UNICEF, 2009). Equally concerning is that some countries which had previously been free of the disease, such as Botswana and Namibia, have also started reporting cases (see Table 1).

\section{Results of qualitative participatory engagement}

Although much is known about the medical and biological dimensions of cholera in the SADC region, the social, political, and cultural dimensions of cholera outbreaks are less well documented. Given this reality, a multi-stakeholder workshop and other methods of participatory engagement were pursued to solicit inputs on these dimensions. A number of key findings emerged from this participatory process.

\section{Interrogating who is responsible for} cholera preparedness and response

One of the key areas of consideration was the issue of 'who is responsible for a response to cholera outbreaks?' On the one hand there is the wellestablished view that governments are responsible for dealing with domestic matters that arise within their borders. This view is backed by a powerful set of international norms which respects the sovereign power of states in their own territories and the practice of non-intervention in the domestic affairs of states (Peters, 2009). To the extent that cholera is an illness that affects people within state boundaries, it can be argued that national governments, and more specifically national health departments and related emergency health response units, are responsible for providing the necessary resources, support and response to deal with this issue. On the other hand, the issue of who is responsible for responding to cholera outbreaks is a 'grey area' in an ever more interconnected and globalised world. A few issues in particular contribute to this complexity.

Firstly, as mentioned earlier, cholera has transboundary dimensions (Funke et al., 2010). The illness therefore does not necessarily remain within the borders of one specific country. When the burden of illness falls on many countries at the same time, critical questions arise about how best to coordinate the distribution of resources, skills and emergency support among different countries.

Secondly, what should happen when governments do not or cannot respond to health crises and fail to deliver on their responsibility to protect and provide for the needs of their citizens? Governments face many challenges when responding to health crises, including budget constraints, lack of healthcare materials, poor maintenance and operation of water infrastructure and weak early warning systems in many countries in the SADC region (Funke et al., 2010). A specific example is the case of the 2008 Zimbabwean cholera outbreak, where one of the aggravating factors was that the health care system had almost completely collapsed as a result of the complex political and economic issues in the country at the time (Balakrishnan 2008; Funke et al., 2010). Therefore hospitals and clinics were

\begin{tabular}{|l|c|c|c|c|}
\hline \multicolumn{5}{|c|}{$\begin{array}{c}\text { Table 1 } \\
\text { Cholera cases reported in SADC member states, 2008-2009 } \\
\text { (Source: United Nations Office for the Co-ordination of Humanitarian Affairs, 2009) }\end{array}$} \\
\hline Country & Reported Cases & Reported Deaths & CFR (\%) & Time Period \\
\hline Angola & 5478 & 60 & 1.2 & 01 Jan. 2008 - 05 Apr. 2009 \\
\hline Botswana & 15 & 2 & 13.3 & 01 Nov. 2008 - 17 Apr. 2009 \\
\hline Malawi & 5170 & 113 & 2.2 & 15 Nov. 2008 - 17 Apr. 2009 \\
\hline Mozambique & 15649 & 133 & 0.8 & 01 Jan. 2009-11 Apr. 2009 \\
\hline Namibia (Inc. AWD) & 203 & 9 & 4.4 & 22 Oct. 2008 - 14 Apr. 2009 \\
\hline South Africa & 12765 & 64 & 0.5 & 15 Nov. 2008 - 10 Apr. 2009 \\
\hline Swaziland (only AWD) & 13278 & 0 & 0 & 22 Dec. 2008-28 Mar. 2009 \\
\hline Zambia & 7412 & 151 & 2.0 & 10 Sep. 2008 - 09 Apr. 2009 \\
\hline Zimbabwe & 95738 & 4154 & 4.3 & 15 Aug. 2008 - 10 Apr. 2009 \\
\hline
\end{tabular}


understaffed, under-resourced and unable to respond to the magnitude of the cholera outbreak.

In some cases governments refuse to acknowledge that they have a cholera outbreak as they fear that such an admission will result in negative repercussions such as reduced trade and investment in the country (Funke et al., 2010). To try to avoid specifically talking about cholera, many governments refer to the problem as acute watery diarrhoea (AWD), which requires a different treatment to cholera and makes the problem seem less urgent (Cumberland, 2009). Lack of political will to take ownership of cholera outbreaks generally leads to time wasted and lives lost. Often when governments are unable or unwilling to respond to cholera outbreaks the onus falls on neighbouring governments and transnational and local non-governmental organisations (NGOs) to step in and handle the crisis.

Thirdly, there is a growing network of transnational and local organisations (WHO, Red Cross, Médecins sans Frontières (MSF), etc.) that have enormous expertise, experience, knowledge and resources when it comes to dealing with cholera outbreaks (Funke et al., 2010). These actors can often provide support that governments themselves are not able to garner in times of cholera crisis. The presence of these transnational actors, however, raises difficult questions. Do these organisations need a government's permission to become involved? What if governments are inadequately responding to cholera outbreaks but do not want the involvement of non-government actors?

Given these complex factors, it is clear that the issue of cholera preparedness and response is nested within a multi-actor, multi-level agency context.

\section{The problem of a reactive response to cholera}

In many developing countries, the approach to cholera outbreaks is a reactive 'emergency response' and directed at controlling the outbreak and minimising mortality. In the event of a cholera outbreak, it is assumed that the health sector in the affected country will take the lead in notifying the relevant national institutions as well as the resident WHO office. The national health sector can officially ask the relevant ministries or departments, other UN affiliates, international non-governmental organisations (INGOs) and non-governmental organisations (NGOs) for financial assistance and/or technical expertise to contain the outbreak. Otherwise, the onus will revert to the WHO to initiate dialogue with the national government in a combined effort to contain the outbreak.

The WHO is the UN affiliate that is responsible for global health issues. WHO operations in UN member states address the health needs of resident populations through collaborations with several partners. These include other UN agencies, donors, international and local NGOs, WHO collaborating centres, the private sector and civil society. The WHO, therefore, takes the lead in assisting member states to prepare and respond to cholera emergencies (World Health Organisation, 2007).

Some countries or regions are completely unprepared when a cholera outbreak occurs. Inconsistency in the development of appropriate policies and their implementation has also been noted (WHO, 2007; 2009). Also, the burden of responding to cholera often lies with the health emergency units in national health departments rather than in an institutionalised section of the department dedicated to a response to cholera in particular. Often emergency health units have to deal with multiple health crises at once (e.g. swine flu and measles), resulting in the units' capacity being stretched too thin to adequately deal with any one crisis in detail (Funke et al., 2010).

\section{Socio-political dimensions of the cholera issue in the SADC region}

What is evident in literature (Cumberland 2009; Schaetti et al., 2009), and has been confirmed in this study's empirical findings, is the widespread awareness that cholera preparedness, response and prevention is a highly politicised issue in many countries.

The International Health Regulations (IHR) provide an indication of high level political involvement in, and recognition of, the issue of communicable diseases. Since 1969, the IHRs have undergone many revisions to the point of their adoption into international law in 2007. The IHRs provide the legal framework for international co-operation for the control of infectious diseases such as cholera (WHO, 2007). Amongst other things, these standards oblige WHO member states to notify WHO of any outbreaks of diseases in their countries that have the potential to cross borders and threaten public health worldwide (Funke et al., 2010). The fact that it has taken so long to award international legal status to these regulations indicates that it is a highly sensitive and political matter to try to convince governments to take ownership of the management of health issues within their sovereign territories. It is an ongoing challenge to implement the IHRs, due to weak political will to do so (Funke et al., 2010).

\section{Socio-cultural dimensions of cholera}

Another issue that has clearly emerged from the literature review and participatory process is the reality that there is a powerful socio-cultural discourse that exists in relation to cholera. This means that it is critical to consider 'community-held ideas, fears and individual help-seeking behaviour regarding the infectious disease' in order to come up with solutions and responses that are relevant and appropriate to specific groups of people (Schaetti et al., 2009). In addition, it is also vital to recognise that cultural beliefs and practice are not homogenous, but differ across time, place and population. Such observations stress the importance of including site-specific analyses when doing research on the acceptance of interventions in response to cholera (Schaetti et al., 2009).

Socio-cultural responses to illness manifest in many different ways. Some communities, for example, see diarrhoea as a normal part of life (Cumberland, 2009). This perception places people at risk as they do not react quickly to the symptoms of cholera. Others see cholera as a disease that is associated with poverty and lack of hygiene (Cumberland, 2009). This 'embarrassing' stigma has been known to cause people to stop talking about the illness and to resist treatment to avoid being exposed to the community's judgement of people who have cholera. This behaviour is problematic because talking about the problem is an important way of addressing it.

Another issue relates to perceptions of trust. Will a specific community primarily turn to western medicine or traditional healers with their health problems? Will a specific person turn to a known community healer or an ad hoc (often foreign-run) cholera relief camp to treat their illness? For example, studies in relation to the viability of a cholera vaccination in Tanzania revealed that there was a perception in some Tanzanian communities that this vaccination would result in infertility (Schaetti et al., 2009).

Also, certain culture-specific behaviour may increase communities' vulnerability to cholera. In terms of religious beliefs, Jehovah's Witness followers, for example, are likely to resist 
treatment via intravenous drip, which is the standard treatment for cholera. In households where polygamy is practiced there is a bigger risk of cholera spreading due to multiple households being linked to each other, either because the women and children live together or because the men move regularly between multiple households. The way that food is consumed and shared is another point for consideration. Are bowls shared or separate? Is food communally prepared by women in a community or do families prepare food separately? It has been found, for example, that high risk points for cholera transmission are large gatherings, such as funerals, where food, drink and space are shared by a crowd of people (United Nations Office for the Co-ordination of Humanitarian Affairs, 2009).

\section{Role of the media in raising the political profile of disasters and thereby attracting funding: the CNN effect}

In recent years, observers of international affairs have raised the concern that the media have increased their ability to affect the conduct of, particularly, United States (US) diplomacy and foreign policy. Dubbed the 'CNN effect', the impact of new global, real-time media is typically regarded as substantial. As part of the $\mathrm{CNN}$ effect, the media may function alternately or simultaneously as: a policy agenda-setting agent; an impediment to the achievement of desired policy goals; and an accelerant to policy decision-making by shortening decision-making response time (Livingston, 1997). While the 'CNN effect' most commonly refers to the effect that news media have on politics and government during political conflict, the media also have a noteworthy effect on decisions made during natural disasters. As videos and images are broadcast worldwide immediately after or even during natural disasters, these images may convince the public to donate money or pressure governments for immediate action. However, sensationalising cholera outbreaks in Africa provides controversial stories for international audiences, and supports the image of Africa as a poverty-stricken, malfunctioning and diseased continent (WHO, 2004a). In addition, selective media coverage means that some cholera outbreaks will attract international attention, commitment to help and resources at the expense of others (Funke et al., 2010).

The media's role is not only negative and can also be useful in terms of performing an educational and knowledge-disseminating function. Public health authorities are generally interested in using the media to provide information on preventative and control measures, i.e. public service announcements. At the same time, however, journalists will often want to focus on spreading or even sensationalising a story. It is therefore important to establish a balance between these 2 interests (WHO, 2004a).

\section{Conclusion}

As is evident from the discussion above, cholera epidemics have been on the increase in Africa, and are not only a health problem but should also be understood and addressed from a social, cultural and political point of view. Concerted efforts are therefore required to establish a proactive long-term strategy consisting of national multi-sectoral and multi-level plans to deal with this issue in a co-ordinated way. Supply of safe water, adequate sanitation, and basic domestic and personal hygiene are critical measures for the prevention and control of cholera and other waterborne and food-borne diseases. Furthermore, governments should prioritise the known high risk areas, as cholera generally affects urban and peri-urban high-density areas more than rural low-density areas. Health education is also key, and messages regarding safe water use and storage, hand washing, safe food handling and disposal of human excreta are important and can be communicated through radio, television, community leaders, schools and public loud speakers.

For these initiatives to succeed, ownership should lie with the national governments of the individual SADC member states. SADC (through, for example its health desk) and the African Union (AU), as well as other governing bodies on the continent, have an important role to play in encouraging national member states to admit to having a problem. This could be done by forming a regional cholera response team and circulating a regional case definition of cholera that should be adhered to by all SADC member states. There is also a need for improved inter- and intra-country co-ordination and information exchange (Funke et al., 2010).

National governments (and specifically their health ministries or departments) need a national response plan whereby they commit individually, with the support of supra-national entities, to addressing cholera outbreak situations. At the same time they also need to communicate with each other during such a situation. However, it is also necessary that public health care entities at the provincial and local level are sufficiently equipped by the national government to deal with cholera outbreaks, as it is at these levels that much of the 'on the ground' response action to cholera takes place. Cholera outbreak management should therefore be co-ordinated at the national level, but clear directions should be given to actors at the sub-national level on how to respond to the outbreak with some level of autonomy and authority (Funke et al., 2010). To this end, mechanisms must be established for ensuring good collaboration between volunteers from NGOs and national health care workers in the field. Developing or maintaining good relationships between key actors may be facilitated by recording details of responsibilities in embassies of United Nations (UN) representations, organising regular briefings and providing regular information on the epidemiological situation and on the effectiveness of outbreak responses (WHO, 2004a).

Instead of constantly reacting to cholera outbreaks, it is suggested that proactive steps be taken to prevent future outbreaks (WHO, 2009; Funke et al., 2010). The need for a proactive rather than a reactive process would allow countries or regions to prevent future outbreaks and pre-plan or respond rapidly during outbreaks. This would be the best way to reduce the risk of community-wide spread of the disease (National Department of Health, 2006). A proactive approach saves valuable time as it replaces the need to first complete an outbreak investigation. In addition, such an approach allows for more rapid implementation of control measures and therefore could save many lives (National Department of Health, 2006).

In order to successfully implement effective cholera prevention and a proactive response plan, short-, medium- and longterm objectives have to be in place to address existing gaps. Also, a proactive response plan needs to make provision for preparedness at local, national, regional and international scale and should be reviewed periodically (Funke et al., 2010).

\section{Recommendations}

As alluded to above, a proactive plan needs to have short-, medium- and long-term objectives, which should include the following: 


\section{Short term:}

- Moving cholera out of the health crisis units of national health departments. A space needs to be institutionalised in national health departments for dealing with, talking about and responding to annual cholera outbreaks. Too often cholera is overshadowed by other, more immediate health crises, such as the recent (2009/10) outbreak of swine flu in the SADC region. In addition, financial resources need to be provided for surveillance, education and additional medical supplies.

- Doing vulnerability mapping of areas that are prone to cholera, due to environmental or infrastructure reasons or other unforeseen reasons (e.g., disasters such as flooding, vulnerability of bordering countries prone to cholera outbreaks and conditions of disaster, political unrest and health system break-down) (Funke et al., 2010).

- Developing an early warning system for prediction of cholera outbreaks due to environmental change (Ford et al., 2009) and compiling a cholera outbreak prevention and response plan. Such a plan describes the step-by-step process of an outbreak response, the logistical arrangements, the need for and quantities of supplies and the list of people serving on the outbreak response team (National Department of Health, 2006).

- Appointing an outbreak response team. This team should consist of a multi-disciplinary and multi-sectoral team contracted to assist with preventing, detecting and containing the outbreak (National Department of Health, 2006).

- Writing a communication plan. This plan should not only structure the communication during the outbreak response but should make provision for structured networks and forums to discuss interim goals and objectives, as well as provide a platform to share and develop the outbreak prevention and response plan within and between different sectors and at different scales (Funke et al., 2010).

- Continuing the implementation of the IHRs. It is important that states are held accountable for keeping to the commitments made by signing these regulations.

- Understanding community specific perceptions and behaviour in those communities that are vulnerable to cholera outbreaks. Such understanding is critical to supporting the process of determining what the most effective and appropriate interventions are for approaching the cholera challenge in the short-, medium- and long-term.

- Recognising that, even where an effort has been made to understand the culture-specific perceptions and behaviour of a community, any solutions or responses to a cholera outbreak need to be locally accepted (rather than imposed in a top-down manner). This entails engaging in the longterm project of education and awareness creation in order to prepare communities for what to expect and do, particularly in high-risk cholera times (such as the rainy season).

\section{Medium term:}

- Tracking incidence and reporting trends for cholera over the last decade.

- Planning for increased timelines of reporting cholera during peak transmission season or at known vulnerable areas, including being on high alert in border areas (National Department of Health, 2006).

- Educating health-care providers and community partners (food and water operators), as well as the general public, regarding the prevention, symptoms, treatment and control of cholera. In addition, general health and hygiene awareness training should be given to vulnerable communities on an ongoing basis. In addition, instructions on the emergency treatment of water and how to mix oral rehydration solutions (ORS) should be given. Education materials should also be prepared for emergency situations (National Department of Health, 2006).

\section{Long term:}

- Ensuring that all people in the country have provision for safe water, sanitation, hygiene and health services. Areas that are known to be prone to cholera outbreaks should be given priority.

- Ongoing education of health workers as well as communities to help with the prevention and management of future outbreaks.

- Strengthened monitoring and surveillance of environmental data as well as disease data to help with early detection and control of cholera outbreaks.

As is evident from the above, responding to cholera in the SADC region is a difficult task. Extensive knowledge and understanding of the unique social, economic and political contexts in SADC states needs to be developed. In addition, adequate sharing and exchange of information are needed to address the challenges that face the successful design and implementation of proactive cholera prevention, preparedness and response strategies. Such strategies should capacitate all actors at different scales and divide responsibilities amongst them, thereby enabling them to make a combined effort to better manage this recurring and debilitating health disaster.

\section{References}

ALBERT MJ, SIDDIQUE AK, ISLAM MS, FARUQUE ASG, ANWARUZZAMAN M, FARUQUE SM and SACK RB (1993) Large outbreak of clinical cholera due to Vibrio cholerae non-O1 in Bangladesh. Lancet 341 1346-1347.

BALAKRISHNAN A (2008) Zimbabwe: from political crisis to cholera epidemic. Guardian News and Media Limited. URL: http:// www.guardian.co.uk/world/2008/dec/04/cholera-zimbabwe-outbreak/print (Accessed: 1 August 2011).

BANDA I (2009) Lack of clean groundwater a health threat. Inter Press Service News Agency (IPS). 9 October 2009. URL: http:// ipsnews.net/africa/nota.asp?idnews=48788 (Accessed 31 July 2011)

BARTRAM J and CAIRNCROSS S (2010) Hygiene, sanitation, and water: forgotten foundations of health. PLoS Med. 7 (11) 1-9.

BORROTO RJ and MARTINES-PIEDRA R (2000) Geographical patterns of cholera in Mexico, 1991-1996. Int. J. Epidemiol. 29 (40) 764-772.

BRADLEY M, SHAKESPEARE R, RUWENDE A, WOODHOUSE MEJ, MASON E and MUNATSI A (1996) Epidemiological features of epidemic cholera (E1 Tor) in Zimbabwe. Trans. R. Soc. Trop. Med. Hyg. 90 378-382.

CRUSH J and FRAYNE B (2007) The migration and development nexus in Southern Africa. Dev. S. Afr. 24 (1) 1-23.

CUMBERLAND S (2009) An old enemy returns: the recent cholera outbreak in Zimbabwe highlights failures in the global fight against an old enemy. Bull. World Health Org. 87 85-86.

DU PREEZ M, VAN DER MERWE MR, CUMBANA A and LE ROUX W (2010) A survey of Vibrio Cholerae O1 and O139 in estuarine waters and sediments of Beira, Mozambique. Water SA 36 615-620.

FUNKE N, JACOBS I, SAID M, NIENABER S and STEYN M (2010) Proceedings, Regional Cholera Response Discussion, hosted by Council for Scientific and Industrial Research, 30 September 2009. CSIR Report No: CSIR/NRE/WR/EXP/2009/0220/A. CSIR, Pretoria.

FORD TE, COLWELL RR, ROSE JB, MORSE SS, ROGERS DJ and YATES TL (2009) Using satellite images of environmental changes 
to predict infectious disease outbreaks. Emerging Infect. Dis. 15 (9) 1341-1346.

GAFFGA NH, TAUXE RV and MINTZ ED (2007) Cholera: a new homeland in Africa? Am. J. Trop. Med. Hyg. 77 (4) 705-713

GOODGAME RW and GREENOUGH WB (1975) Cholera in Africa: a message for the West. Ann. Intern. Med. 82 101-106.

GORBACHEV M (2002) Special message. In: Turton A and Henwood R (eds.) Hydropolitics in the Developing World: A Southern African Perspective. African Water Issues Research Unit, Centre for International Political Studies, Pretoria.

HENSYL WR (ed.) (2000) Bergey's Manual of Determinative Bacterio$\log y\left(9^{\text {th }}\right.$ edn. $)$ Lippincott, Williams and Wilkins, Philadelphia.

KIEM E (2009) Cholera outbreaks raise concern in nine Southern African countries. URL: http://www.unicef.org/health/index 48553.

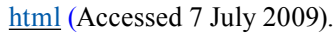

LIN W, FULLNER KJ, CLAYTON R, SEXTON JA, ROGERS MB, CALIA KE, CALDERWOOD SB, FASER C and MEKALANOS JJ (1999) Identification of a Vibrio cholerae RTX toxin gene cluster that is tightly linked to the cholera toxin prophage. Proc. Natl. Acad. Sci. 96 1071-1076.

LIVINGSTON S (1997) Clarifying the CNN effect: an examination of media effects according to type of military intervention. John F. Kennedy School of Government's Joan Shorenstein Center on the Press, Politics and Public Policy, Harvard University.

LONGINI IM Jr, NIZAM A, ALI M, YUNUS M, SHENVI N and CLEMENS JD (2007) Controlling endemic cholera with oral vaccines. PLoS Med. 4 (11) 336.

MINTZ ED and GUERRANT RL (2009) A lion in our village - the unconscionable tragedy of cholera in Africa. New Engl. J. Med. $\mathbf{3 6 0}$ (11) $1060-1063$

NATIONAL DEPARTMENT OF HEALTH (2006) Draft national guidelines on epidemic preparedness and response. Emerging and re-emerging infectious diseases (ERID), Communicable Disease Control, National Department of Health, South Africa.

RAMAMURTHY T, GARG S, SHARMA R, BHATTACHARYA SK, NAIR GB, SHIMADA T, TAKEDA T, KARASAWA T, KURAZANO H, PAL A and TAKEDA Y (1993) Emergence of a novel strain of Vibrio cholera with epidemic potential in Southern and Eastern India. Lancet 341 703-704.

SACK DA, SACK RB, NAIR GB and SIDDIQUE AK. Cholera. Lancet 363 223-233.

SCHAETTI C, HUTUBESSY R, ALI SM, PACH A, WEISS MG, CHAIGNAT C and KHATIB AM (2009) Oral cholera vaccine use in Zanzibar: socioeconomic and behavioural features affecting demand and acceptance. BMC Public Health 9 (99) 1-11.

SHAPIRO RL, OTIENO MR, ADCOCK PM, PHILLIPS-HOWARD PA, HAWLEY WA, KUMAR L, WAIYAKI P, NAHLEN BL and SLUTSKER L (1999) Transmission of epidemic Vibrio cholerae O1 in rural western Kenya associated with drinking water from Lake Victoria: An environmental reservoir for cholera? Am. J. Trop. Med. Hyg. 60 (2) 271-276.

SOUSSAN J (2003) Poverty, water security and household use of water. International Symposium on Water, Poverty and Productive Uses of Water at the Household Level, 21-23 January 2003, Muldersdrift, South Africa.

SUR D, LOPEZ AL, KANUNGO S, PAISLEY A, MANNA B, ALI M, NIYOGI SK, PARK JK, SARKAR B, PURI MK, KIM DR, DEEN JL, HOLMGREN J, CARBIS R, RAO R, NGUYEN TV, DONNER A, GANGULY NK, NAIR GB, BHATTACHARYA SK and CLEMENS JD (2009) Efficacy and safety of a modified killedwhole-cell oral cholera vaccine in India: an interim analysis of a cluster-randomised, double-blind, placebo-controlled trial. Lancet 374 (9702)1694-702.

SWATUK L (2009) Neoliberalism, globalism and the poverty trap in Southern Africa. In: Pressend M and Othieno T (eds.) Rethinking Natural Resources in Southern Africa. Institute for Global Dialogue, Midrand.

THE AMERICAN HERITAGE MEDICAL DICTIONARY (2007) The American Heritage Medical Dictionary. URL: http:// medical-dictionary.thefreedictionary.com/serovar (Accessed 8 August 2011).

UNITED NATIONS (2009) The Millennium Development Goals Report 2009. United Nations, New York.

UNICEF (UNITED NATIONS CHILDREN'S FUND) (2009) Cholera outbreaks raise concern in nine Southern African countries. URL: http://www.unicef.org/health/index_48553.html (Acessed: 17 December 2009).

UNITED NATIONS OFFICE FOR THE CO-ORDINATION OF HUMANITARIAN AFFAIRS (2008) Regional Update No. 2 Cholera Outbreaks in Southern Africa, 24 December 2008. United Nations Office for the Co-ordination of Humanitarian Affairs, Pretoria.

UNITED NATIONS OFFICE FOR THE CO-ORDINATION OF HUMANITARIAN AFFAIRS (2009) Regional Update No. 9 Cholera or Acute Watery Diarrhoea Outbreaks in Southern Africa, 17 April 2009. United Nations Office for the Co-ordination of Humanitarian Affairs, Pretoria.

WACHSMUTH K, OLSVIK Ø, EVINS GM and POPOVIC T (1994) Molecular epidemiology of cholera. In: Wachsmuth K, Blake PA and Olsvik Ø (eds.) Vibrio cholerae and Cholera: Molecular to Global Perspectives. American Society for Microbiology, Washington D.C. pp. 357-370.

WHO (WORLD HEALTH ORGANISATION) (1993) Guidelines for Cholera Control. Cholera Prevention and Control Handbooks. World Health Organisation, Geneva.

WHO (WORLD HEALTH ORGANISATION) (2000) Cholera. Fact sheet No. 107. URL: http://www.who.int/inf-s/en/fact107.html (Accessed 15 January 2010).

WHO (WORLD HEALTH ORGANISATION) (2001) Cholera 2000. Weekly Epidemiological Record 76 (31) 233-240.

WHO (WORLD HEALTH ORGANISATION) (2004a) Cholera outbreak: assessing the outbreak response and improving preparedness. Global Task Force on Cholera Control. Document No. WHO/ CDS/CPE/ZFK/2004.4. Geneva. URL: whqlibdoc.who.int/hq/2004/ WHO CDS CPE ZFk 2004.4 eng.pdf (Accessed 20 January 2010).

WHO (WORLD HEALTH ORGANISATION) (2004b) Cholera vaccines: a new public health tool? Global Task Force on Cholera Control, report for WHO meeting, 10-11 December 2002, Geneva. World Health Organisation, Geneva.

WHO (WORLD HEALTH ORGANISATION) (2006) Cholera surveillance and number of cases: cholera cases - annual summaries (1995-2006). Geneva. URL: http://www.who.int/topics/cholera/surveillance/en/index.html (Accessed 20 January 2010).

WHO (WORLD HEALTH ORGANISATION) (2007) Resolution: Resurgence of cholera in the World Health Organisation African region: current situation and way forward. $57^{\text {th }}$ Session of the WHO Regional Committee. Document AFR/RC57/3. World Health Organisation, Regional Office for Africa, Brazzaville.

WHO (WORLD HEALTH ORGANISATION) (2008) A snapshot of drinking water and sanitation in Africa. A regional perspective based on new data from the WHO/UNICEF Joint Monitoring Programme for Water Supply and Sanitation. Prepared for AMCOM as a contribution to the 11th Summit of Heads of State and Government of the African Union with special theme: Meeting the Millennium Development Goal on Water and Sanitation, 30 June to 1 July, 2008. World Health Organisation, New York, and UNICEF, Geneva.

WHO (WORLD HEALTH ORGANISATION) (2009) Cholera in Zimbabwe - update 4, 9 June 2009. URL: http://www.who.int/csr/ don/2009 06 09/en/index.html (Accessed 7 July 2009).

WHO (WORLD HEALTH ORGANISATION) (2010) Cholera vaccines: WHO position paper. Weekly Epidemiological Record 85 (13) 117-128.

ZUCKERMAN JN, ROMBO L and FISCH A (2007) The true burden and risk of cholera: implications for prevention and control. Lancet Infect. Dis. 7 (8) 521-530. 